\title{
Building up European identity in primary education
}

\author{
Claudia BORCA, Calin RUS, Simona SAVA•
}

\section{Abstract:}

Building up the personal identity is a lifelong process, as identity can change, according with the groups of belonging, with new knowledge and changes of beliefs and contexts. There are more stable components of identity, like the values and attitudes, but there are contexts and experiences that sharpen different aspects of the identity. The article argues that education systems in Europe have responsibilities in supporting learners to develop their competences to act as citizens at local, national and European levels and thus have also the legitimacy to contribute to the development of a European identity and of a sense of belonging to Europe. Furthermore, it argues that such a process can and should start already in early ages. Therefore, teachers in primary school need appropriate competences to foster a positive identification of children with Europe and European values. They need to master intercultural competence, appropriate pedagogical and methodological approaches, they need to reflect on how to design teaching and learning contexts meant to stimulate, in a joyful, playful, attractive and consistent manner the building up of a European identity. The article mirrors the training needs of primary school teachers of $3^{\text {rd }}$ and $4^{\text {th }}$ grade in Western Romania, to develop these competences and be able to foster such process. The assessment of the training needs of primary school teachers involved covered all aspects of the competence, including values, attitudes, as well as the knowledge about EU, and their reflection on their teaching practices. The conclusions of the analysis can be useful for further training programs and reconceptualization of (initial) teacher education.

Key words: European identity, primary school education, teacher training, intercultural competence

\section{Introduction}

The European Union (EU) is not only a social, economic and administrative construct, but also a cultural and educational one. Education plays a crucial role in building up the sense of belonging and identification with this construct, with this space, where different identities co-exist, different cultures meet, and need to be understood, known, accepted and valorized (Ghisoiu, 2012). The EU is an imagined construct, an ongoingly emerging space, a project to be continuously built, (re)created, (re)shaped in a constructive way.

\footnotetext{
- Claudia Borca - Senior Lecturer PhD, Department of Educational Sciences, West University of Timisoara Calin Rus - Associate researcher PhD, West University of Timisoara, Director of the Intercultural Institute Timisoara Simona Sava - Prof. PhD, Department of Educational Sciences, West University of Timisoara
} 
The EU as a political project is strongly associated with a set of explicit democratic values and a sense of belonging to Europe and to the EU has to be connected with these values. However, in recent years, the EU construct was heavily challenged and questioned, by different crisis, tensions, growing populist and nationalist attitudes, tendencies of segregation, racist and xenophobic manifestations. Such phenomena, generated by approximative, superficial knowledge (E. Morin, apud A. Chermeleu, 2016), proved that by "standardizing ways of life at the European level it is not enough to create a European culture" (Chermeleu, 2016). The rapid changes generate confusion and the feeling of insecurity, multiplying the phenomena of acculturation. The homo digitalis is even more exposed to this situation, needing to be properly equipped with relevant knowledge and critical analysis skills and an open-minded attitude, to decode, understand, accept other cultures, while being confident about his own roots. Thus, in order to re-create the shared and more consistent European ethos, Adia Chermeleu argues for an "education of comprehension", for a proper understanding of the complex effects of the Europeanization, both beneficial and harmful, for dedicated pedagogic actions of teachers as cultural mediators, in order to build the "transcultural competence", understood as "capitalizing the other cultures, while insourcing the own values" (Chermeleu, 2016), to build the solidarity with the European values, and the capacity to live and understand multiple identities, and the European destiny (Catarci, 2014; Bruter, 2005).

The explosion of cultural references, the mixing up of cultural models and knowledge, in the pluricultural societies, and the ever-diverse Europe have consequences on structures of identity and social integrity. The European identity, as social identity, as supranational and complementary to the national identity, is seen as a precondition of the wellfunctioning of the European Union, but also as viable solution for building self-esteem and sense of belonging to people with migrant background, to the mobile citizens of Europe, as in "ethnically diverse contexts, European identity has a higher potential than national identities to become a unifying common identity" (Agirdag, Phalet, Van Houtte, 2016; Duchesne \& Frognier, 2008; IEA, 2017 - see Losito et all; EC, 2018). Therefore, for a well-functioning society and European Union, a bi-dimensional model of identity, both national and European, is to be favored, combining "shared sense of nationhood, the recognition and affirmation of distinctive (ethnic) identities, ...., creation of multiple identities" (Agirdag, Phalet, Van Houtte, 2016), together with developing the sense of belonging to different communities, reshaped, enlarged or comprised, mixed-up, in the liquid society (Hooge \& Verhaegen, 2017; Catarci, 2014).

This means ensuring proper knowledge and positive attitudes towards the European values of freedom, equality, tolerance and non-discrimination, respect for human rights, peace and democratic principles and culture, openness towards the histories, ideas, confessions, traditions, heritage and landscapes (EC-Eurydice, 2017; Catarci, 2014; Hadler, Tsutsui \& Chin, 2012; Bruter, 2005). Thus, the education systems, all over Europe, are asked to nurture the building up of the European identity, and equal opportunities for 
every child, starting this life-long lasting process from early ages, with solid fundaments, based on appropriate knowledge about its meaning, role and values, ways of functioning and purpose, creating this way positive attitudes of well informed and open-minded, active citizens, with a solid democratic culture (EC-Eurydice, 2016; Council of Europe, 2018).

Studies show that European identity, as a multinational civic identity, is a more, permeable and more inclusive category than often implicitly ethnically-defined national identities. European affiliation correlates positively with better school achievements (Agirdag et all, 2012, 2016; Grad et all, 2004; Losito at all, 2017 - IEA), especially in multicultural schools and societies, and for the migrant groups. The two social identities, the national and the European one, are not mutually exclusive categories. On the contrary, they positively complement each other, as the Ingroup Projection Model shows, proving that "the higher the level of the superordinate category, the more easily groups can be counted as being part of that identity" (Agirdag, Phalet, Van Houtte, 2016; Duchesne \& Frognier, 2008; Reicher, Spear, \& Haslam, 2010; Rus \& Chermeleu, 2019).

Both national and European identification are emerging categories for the children between 6 and 10 years old, and the awareness of belonging to the European supranational group peaks around 10 years old (Barrett, 2007; Duchesne \& Frognier, 2008; Agirdag, Phalet, Van Houtte, 2016). Therefore, dedicated activities, programs, projects are to be run in primary education.

This leads to the need to identify to what extent the teachers in primary education in Western Romania are fostering building up the European identity to their pupils, and what are their training needs for doing this in an appropriate manner.

\section{Training of teachers for building up European identity}

Teachers are the main actors and professionals expected to strengthen, through intercultural education, education for democratic citizenship and human rights education the competences needed for democratic culture. This is best done in an integrative and trans-curricular manner, aimint at a "European positive and inclusive sense of belonging, complementing the local, regional and national identities and traditions" (Council of Europe, 2018). Therefore, teachers need proper training, proper knowledge, methodologies, and a positive attitude, to be able to create authentic, active and attractive learning environments and situations, to support pupils in developing a European identity (Sales Giges, \& Garcia Lopez, 1998; Nedelcu, 2008).

Unfortunately, as the Eurydice study show (2017), in almost half of the member states there is no national curriculum reference and policy for including citizenship education in initial teacher training, or as entrance examination into the teaching career, Romania being among them. The same situation is true for the continuing professional development opportunities, the Eurobarometer (2018) identifying a remarkably low level of knowledge of the EU, mainly among the older teachers. In addition, the study carried out by Badescu at all (2018), in line with the World Values Survey (2014), aiming 
to identify the attitudes of the Romanian teachers towards the democratic societies, highlights a worrying high percentage of teachers (45\%) having a low attachment towards a democratic regime, even higher percentages being identified amongst the young teachers, with a lower level of social tolerance as well. However, the trust in EU and its institutions is quite high $(47,7 \%)$, on the third place after the army and the police. Obviously, the current policies and measures implemented at national level are not enough to secure a proper attitude and competence of teachers to foster the European identity. However, national initiatives to stimulate proper training of teachers and a more extensive focus on European issues do exist in Romania. Thus, since 2004, the national competition for schools to get the label of "European school", aims at stimulating appropriate management of schools, their culture and ethos with reference to the European dimension in education. Through common European projects, partnerships, programs and activities. Also, the moto of the Romanian Presidency of the European Council in 2019 was "Cohesion, a common European value", showing commitment towards ensuring a cohesive and inclusive Europe. There are existing national stipulations concerning the optional subject of intercultural education and of civic education included in the curriculum for pre-service training of teachers, both in primary school, and in the pedagogic module aiming to prepare for the teaching career the teachers of secondary school and high school. But it is no guarantee that this happens with the needed extension, as it is up to the institutional autonomy, both in pre and inservice training. Thus, more determined actions are to be taken by teacher educators in universities and not only (Dias \& Soares, 2017), to ensure proper knowledge and training, teaching resources and guidelines, dedicated sites and materials, to help teachers of all specializations to master the pedagogy of diversity, being able to design participatory trans-curricular learning environments on citizenship and diversity (Nedelcu, 2008; Council of Europe, 2018).

Teachers of primary school, both the class-teachers and the teachers of languages, are more likely to have dedicated training on intercultural education and cultural diversity than the ones in secondary schools (Petrescu, 2012). Also, the teachers in primary education have more possibilities to act in an integrative, trans-curricular manner, as they are teaching most of the subjects in the class. They have even the possibility to introduce a whole optional subject in their curriculum design. But they do not really use this possibility, as previous studies done at West University of Timisoara (Ilie, 2016) show. Teachers have a certain fear to use pedagogic concepts in curriculum design (Ilie, 2016; Nedelcu, 2008; Petrescu, 2012), and, even when they were provided with teaching materials and resources and the tailored training, they were not so enthusiastic to introduce a whole dedicated subject. Their proffered choice was to approach the topic of Europe and European identity in compulsory subjects (at geography and history, for instance), or as specific, additional topics, mainly in non-formal activities, but not on a regular basis. 
As our findings show, even when provided with guidelines, manuals, materials, examples developed in the previous Jean Monet projects (Ilie, 2016), teachers need training to acquire appropriate knowledge and critical understanding about European Union, its policies, legal framework and institutional arrangements, to be confident enough to teach their pupils on a regular basis and on more advanced issues than about flags, symbols, and European Day. Therefore, a compendium about Europe was also provided (Rus and Chermeleu, 2019), covering issues about European history, emergence and evolution of the European Union, European law and institutions, with distinct references on how to build a European identity in a sustainable manner, with the view towards 2030, and using the European Reference Framework of Competences for Democratic Culture, launched by the Council of Europe (2018, with adaptations for primary education in 2019). These are, however, isolated initiatives. Even available as open educational resources, they have still a relatively low visibility and practical use in education practice, needing more dissemination.

To ensure that primary school teachers have the right mixt of values, attitudes, skills and knowledge, associated with critical understanding about European Union and its diversity in order to foster a European identity, several actions are needed. There is a need to provide, even from preservice training, an integrative, interdisciplinary and transversal civic education, making sure that teacher get relevant knowledge supporting in-depth understanding of the principles and core values of democracy in general and of the values of the European Union, together with knowledge on policies, history, law, and culture of Europe and of its member states. They have also to be enabled with methodologic capacities to conceptualize, design, implement and evaluate learning contexts using a wide range of methods, resources and tools for an attractive, joyful and playful, cooperative learning, inside and outside the classroom. Teachers need also to develop their own social competences, necessary for encouraging discussions and debates in the classroom, for involving the pupils in the school and in the community life, building in the same time relevant partnership with stakeholders in the community. Lastly, teachers need self-reflection and self-evaluation capacity, as well as autonomous learning skills enabling them to continuously improve their competences, to undertake transformative action, and to be aware of their own values, stereotypes and attitudes (Eurydice, 2017; Nedelcu, 2008) concerning the cultural diversity of the European ethnocultural space, being able to act as a "cultural broker". To what extent the teachers in primary education are equipped in initial teacher education, and also updated and upskilled in continuing professional development is to be identified, for tailored action. Thus, a dedicated training needs analysis is further illustrated.

\section{Methodology}

In order to find appropriate answers to the question "To what extent teachers in primary education have appropriate knowledge, skills and attitude about European Union and the European identity?", data from two sources have been collected and analyzed. 
First, a questionnaire-based survey was designed, aiming to identify the educational practices in this regard, as well as their training needs of a group of teachers having pupils on $3^{\text {rd }}$ and $4^{\text {th }}$ grade. The questionnaire, administered both online and paper-based, was designed in line with the items of the Eurobarometer (European Commission, 2018) and the IEA survey (2016 - see Losito et all, 2017), and compatible with the questionnaire designed by the University of Bremen on "European citizenship".

The questionnaire has three parts, on assessment of values (A), of knowledge and attitudes about the EU (B), and on teaching practices and needs (C).

Secondly, qualitative data on these issues was obtained from the participants, also teachers of primary school, involved in the piloting of descriptors of competences for democratic culture adapted for children below age 10 .

In parallel, a curriculum analysis of national curricula for these grades was also performed, to situate the responses in the context of existing educational policies and curriculum requirements.

\section{Results}

31 teachers provided responses to the questionnaire and 24 attended the workshop on descriptors. Their feedback had a high degree of coherence and a relatively low level of variability. This allowed for the identification of some key ideas which are presented below without quantitative details.

Teachers involved display clearly and consistently predominantly positive attitudes towards the EU, considering that EU had a positive impact on themselves as individuals, on their region and on Romania.

While the assessment of the economic impact reveals a more balanced perspective, there is a clear consensus on the fact that EU had a strong positive impact on the protection of the rights of citizens. To a very large extent participants disagree with the common negative perspective on the EU portrayed in the media as a bureaucracy wasting time and money. On the contrary, there is a strong emphasis on the fact that the EU has an important contribution to ensuring peace in Europe and a significant impact on global matters. However, there is an even distribution of responses with regards to the impact of the EU on cultural identity and on diversity in society. Thus, a significant proportion of teachers consider that the EU poses a certain degree of risk to cultural identity. The degree of identification with the local and national level is significantly higher than the identification with Europe and with the global human community.

There is a strong acknowledgement of the need for teachers to know more about the EU and about other countries in Europe, as well as to do more to support their students to acquire such knowledge. There is also confirmation of the limited information participant teachers have about their rights as EU citizens and a moderate interest about EU affairs. Teachers also welcome to a very large extent having more opportunities and support to reflect on European identity and its consequences. 
With regards to the knowledge about the EU, the most common elements are generally widely known, including founding countries, current membership, anthem and motto. However, teachers involved have much less information about the history of the EU, but also about the EU values. While human rights, freedom and democracy are without doubt considered as key European values, there is less consensus regarding human dignity, as a source of human rights, as well as regarding the importance of solidarity.

In terms of rights and benefits provided by the EU to its citizens, teachers focus almost exclusively on the freedom of movement.

The review of the actual teaching practice related to Europe and the EU shows that in most cases teachers address European topics between once and three times per school year, which means that most probably national references have a much stronger presence in educational activities. This is related to some extent to the limited opportunities provided explicitly by the curriculum, but also to the fact that many teachers consider that children at this age are not able to understand certain issues about other countries and the EU. Many consider that the most appropriate approach is to allocate certain specific activities to Europe a few times per year, as extraordinary additional aspects, for example on special occasions, on Europe's Day or in projectrelated activities. There is also little awareness of the educational potential represented by reflection on European values in relation to daily life and school situations.

In addition, when activities are organized for children to learn about other countries, the emphasis is on simple facts and aspects like the flag, monuments, official language, etc, with certain risks of over-simplification and therefore reproduction of stereotypes. Also, the other countries are presented as if they were culturally homogeneous and the EU as being a mosaic of clearly separated and differentiated entities.

\section{Discussions and conclusions}

The results obtained prove that the questions regarding the legitimacy of addressing European aspects and supporting the development of a sense of belonging to Europe are far from clear among primary school teachers. The Council of Europe (2018) and the Council of the EU (2018) are very clear in underlining that promoting EU values and developing competences for democratic culture, including knowledge and critical understanding of the self with one's multiple affiliations, including European belonging, should be an essential part of the mission of schools. Therefore, both national policy documents and the initial and in-service teacher training programs should pass this message to teachers in an explicit way, allowing of course for critical reflection and supporting teachers to become aware of their responsibility and their importance in this respect.

The other key issue is whether such a goal is achievable at the age of primary school. Many teachers consider that very little can be done at this age and prefer to take the easy way of remaining at a superficial level of European symbols, list of countries with their flags and location on the map, therefore limiting the learning to simplified knowledge. 
However, as the Council of Europe (2018) emphasizes, in order to have a functional democratic culture at local, national and European levels, young people need values, attitudes, skills, together with knowledge and critical understanding.

Klitmøller and Jensen (2019) prove, based on experiences in Denmark, that it is possible and desirable for teachers at primary level to focus on developing the critical understanding of children, their attitudes towards self and others enabling democratic and intercultural processes, as well as the skills needed for such processes, with an emphasis on deliberation, respectful exchanges and critical reflection.

This shows therefore the need for teachers training programs to incorporate examples, illustration and arguments for the possibility of such activities with primary school students (Savvides, 2006). In addition, the creativity and adaptability of teachers should be encouraged, so that they become able and confident to design educational interventions in line with these goals. In this context, the on-going work of the Council of Europe to provide descriptors of competences for democratic culture adapted for children below age 10 can significantly facilitate the work of teachers and encourage them to include activities on these topics.

Making it clear to teachers that human rights education activities, activities related to values or focused on the development of critical thinking should also be seen in the context of promoting European belonging and awareness.

It is obvious that, as our results also point out, teachers need support in both the development of their own competences for democratic culture, and pedagogical competences to support students to develop these competences in an appropriate way. Having good intentions is not enough and not managing such sensitive issues in the right way may actually lead to opposite and undesired results. Therefore, teachers need to be supported in planning and managing interactive, engaging and adapted activities and allow children to develop the full range of elements of competence, without insisting exclusively on knowledge or replicating moralizing messages.

It appears important for teachers to be informed about the EU and the major European current issues, but it is even more important that they truly adhere to the European values and illustrate them on a daily basis in their behavior and interaction with students, with parents and with community members. For this, tools, support and training is essential and one of the concerns should be on the development of skills of reflection on teaching practice and of self-reflection, which would enable teachers to take ownership of the way they manage the task of supporting primary school students in feeling European and in acting according to European values.

\section{Acknowledgements}

This study was produced as a part of the PEREV Project - „Penser, raconter, vivre L'Europe à l'école" (587757-EPP-1-2017-1-ROEPPJMO-PROJECT), a Jean Monet project that has received funding from the European Union's Erasmus+. As part of the project, it 
was organized in July 2019 the International Conference "Identité Europeenne en question". The papers reunited in this volume are selected presentations at the conference.

The study reflects only the authors' view. The Research Executive Agency of the European Commission is not responsible for any use that may be made of the information it contains.

\section{References:}

Agirdag, O., Huyst, P., \& van Houtte, M. (2012). Determinants of the Formation of a European Identity among Children: Individual- and School-Level Influences. JCMS: Journal of Common Market Studies, 50(2), 198-213. https://doi.org/10.1111/j.14685965.2011.02205.x

Agirdag, O., Phalet, K., Van Houtte, M. (2016). European identity as a unifying category: National vs. European identification among native and immigrant pupils. European Union Politics. 17(2) 285-302. DOI: 10.1177/1465116515612216

Bădescu, G. Negru-Subțirică, O., Angi, D., Ivan, C. (2018). Educatie pentru democratie in scolile din Romania. http://library.fes.de/pdf-files/bueros/bukarest/14767.pdf

Barrett, M. (2007). Children's Knowledge, Beliefs and Feelings about Nations and National Groups. Hove: Psychology Press.

Bruter, M. (2005). Citizens of Europe? The emergence of a mass European identity. Basingstoke: Palgrave Macmillan.

Catarci, M. (2014). Intercultural education in the European context: key remarks from a comparative study. Intercultural education. 25(2): 95-104.

https://doi.org/10.1080/14675986.2014.886820

Chermeleu, A. (2016). Education and culture in the age of globalization. Journal of Educational Sciences. 2(34), 3-9. Timisoara : Ed. Universitatii de Vest

Council of Europe (2018) Reference Framework of Competences for Democratic Culture (3 volumes). Strasbourg, Council of Europe Publishing

Council of the EU (2018). Council Recommendation on promoting common values, inclusive education, and the European dimension of teaching. C195/1. Brussels: Official Journal of the European Union. https://eur-lex.europa.eu/legalcontent/EN/TXT/PDF/?uri=CELEX:32018H0607(01)\&from=EN

Dias, D. \& Soares, D. (2017). Civic learning outcomes: a step towards an inclusive higher education, International Journal of Inclusive Education, DOI: 10.1080/13603116.2017.1365956

Duchesne, S., \& Frognier, A.-P. (2008). National and European Identifications: A Dual Relationship. Comparative European Politics, 6(2), 143-168. https://doi.org/10.1057/palgrave.cep.6110128

European Commission (EC). (2018). European Citizenship - Standard Eurobarometer 89 Report. Luxembourg: Publications Office of the European Union 
European Commission/ Eurydice. (2017). Citizenship education at school in Europe. Luxembourg: Publications Office of the European Union. doi:10.2797/778483

European Commission/ Eurydice. (2016). Promoting citizenship and the common values of freedom, tolerance and non-discrimination through education. Luxembourg: Publications Office of the European https://publications.europa.eu/en/publication-detail/-/publication/ebbab0bb-ef2f11e5-8529-01aa75ed71a1/language-en

Faas, D. (2007). Youth, Europe and the Nation: The Political Knowledge, Interests and Identities of the New Generation of European Youth. Journal of Youth Studies, 10(2), 161-181. https://doi.org/10.1080/13676260601120161

Grad, H., Ros, M., García-Albacete, G., \& Rodríguez-Monter, M. (2004). The Meaning and Importance of European Identity and its Relationship to Regional and National Identities in Spain: Some Contributing Factors to the Development of European Identity. Sociológica, 36(3), 219-236.

Ghisoiu, C. (2012). Identitate in Uniunea Europeana. Bucuresti: Ed. Universitatii din Bucuresti

Hadler, M., Tsutsui, K., \& Chin, L. G. (2012). Conflicting and reinforcing identities in expanding Europe: Individual- and country-level factors shaping national and European identities, 1995-2003. Sociological Forum, 27(2), 392-418. https://doi.org/10.1111/j.15737861.2012.01323.x

Hooghe, M., \& Verhaegen, S. (2017). The effect of political trust and trust in European citizens on European identity. European Political Science Review, 9(02), 161-181. https://doi.org/10.1017/S1755773915000314

Ilie, M. (2016). European Union Citizen - an optional discipline in Romanian primary schools, two EACEA projects. Journal of Educational Sciences. 2(34), 81-88. Timisoara: Ed. Universitatii de Vest

Klitmøller, J., Jensen, S. (2019). Bildung, Motivation, and Deliberative Democracy in Primary Education. In Hviid, P., Martsin, M. (Eds.), Culture in Education and Education in Culture - Tensioned Dialogues and Creative Constructions, p.29-45. Heidelberg: Springer

Losito, B., Damiani, V., Agrusti, G., Schulz, W. (2017). Young People's Perceptions of Europe in a Time of Change IEA international Civic and Citizenship Education Study 2016. International Association for the Evaluation of Educational Achievement (IEA). Amsterdam: Springer Open.

Nedelcu, A. (2008). Fundamentele educatiei interculturale - Diversitate, minoritati, echitate. Iasi: Polirom

Petrescu, A. C. (2012). Formarea profesorului de limbi straine din invatamantul prescolar si primar din Romania - Schimbari de paradigma in contextul profesionalizarii. Bucuresti: Ed. Universitatii din Bucuresti. 
Reicher, S. D., Spears, R., \& Haslam, S. A. (2010). The social identity approach in social psychology. In M. S. Wetherell \& C. T. Mohanty (Eds.), The SAGE handbook of identities (pp. 45-62). Thousand Oaks, CA: Sage.

Rus, C., Chermeleu, A. (2019). Thinking Europe in School. Timisoara: Editura Universitatii de Vest

Sales Giges, A. \& Garcia Lopez, R. (1998). Teacher Training with a View Towards Developing Favorable Attitudes Regarding Intercultural Education and Cultural Diversity. European Journal of Intercultural Studies. 9(1): 63-77. https://doi.org/10.1080/0952391980090105

Savvides, N. (2006). Developing a European identity: a case study of the European School at Culham. Comparative Education. 42(1): 113-129. https://doi.org/10.1080/03050060500515801 